Review Article

\title{
Nuclear Power's Potential for Carbon Emission Reduction in Chinese Mainland Based on Real Data and Scenario Analysis
}

\author{
Yunna Wu, Kaifeng Chen* \\ School of Economics and Management, North China Electric Power University, Beijing, China \\ Email address: \\ ckfhdchina@126.com (Kaifeng Chen) \\ ${ }^{*}$ Corresponding author
}

To cite this article:

Yunna Wu, Kaifeng Chen. Nuclear Power's Potential for Carbon Emission Reduction in Chinese Mainland Based on Real Data and Scenario Analysis. American Journal of Software Engineering and Applications. Vol. 5, No. 6, 2016, pp. 46-55. doi: 10.11648/j.ajsea.20160506.12

Received: November 23, 2016; Accepted: December 10, 2016; Published: January 16, 2017

\begin{abstract}
China's economic growth prompted the increase in carbon emissions for the past years, which has been caught the attention from the government. Actually, a large share of China's carbon emissions is produced by the electricity sector. And that means the electricity sector plays a key role in emission reduction. Carbon emission reductions during 2009 to 2013 have been estimated and calculated in this paper, and nuclear power shows the potential for emission reductions. Then, China's nuclear power potentials for carbon emission reduction from 2015 to 2025 have been predicted and expected under three scenarios. Finally, conclusions show emission reductions under the American scenario is highest. However, only $2 \%$ of China's energy is from the atom, which should be paid more attention to. On executive orders and policies, the Chinese Government should provide more and substantial supports for China's nuclear power development.
\end{abstract}

Keywords: China's Nuclear Power, Carbon Emission Reduction, Potential, Scenario Analysis

\section{Introduction}

Since 2000, worldwide energy consumption showed growth trend, with an average growth rate of $2.44 \%$, except for negative growth in 2009 (-1.22\% compared to 2008). Global primary energy consumption increased by $2.3 \%$ in 2013. The total reached 12730.4 Million tons oil equivalent, with a main contribution from China $(22.41 \%)$, US (17.8\%), Russia (5.49\%), and India (4.67\%) [1]. Meanwhile global carbon emissions were also growing, with an average growth rate of $2.54 \%$, except for negative growth in $2009(-1.51 \%$ compared to 2008). By 2013, global carbon emissions have achieved 35.09 billion tons, with China (27.1\%), US (16.9\%), India (5.5\%), Russia (4.9\%) and Japan (4\%) as the most producers [1]. Figure 1 shows the corresponding growth of energy consumption and chart carbon emissions. As can be shown in Figure 1, energy consumption and carbon emissions were positively correlated. And China has the highest number of energy consumption and carbon emissions. Though China's economy has made a rapid development, it also wasted too much resource and polluted environment badly. The efficient use of resources and carbon emissions reduction become problems confronted and concerned by the Chinese government. The Chinese government has made a solemn commitment to cut the $\mathrm{CO} 2$ emissions per unit of GDP by $40 \%-45 \%$ by year 2020 off the year 2005 level at the Copenhagen Conference [2]. According to China's 12th Five Year Plan (12-5YP), the goal is to lower CO2 intensity by $17 \%$ by 2015 from the 2010 level [3]. However, it's hard to achieve the goal, given that Chinese carbon emissions continue to grow. 


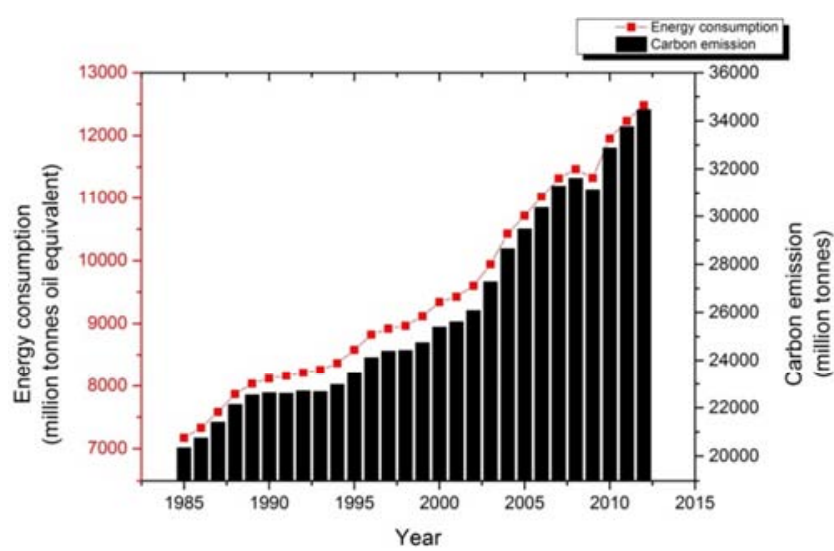

Figure 1. The world's energy consumption and carbon emissions from 183 to 2013.

The power sector consumes a huge amount of fossil fuel with bringing a large amount of greenhouse gas emissions. According to the US Environmental Protection Agency (EPA), electricity is the largest single source of $\mathrm{CO} 2$ emissions in the nation, accounting for about $38 \%$ of total $\mathrm{U}$. S. CO2emissions in 2012 [4]. In China, the electricity sector consumes approximately $50 \%$ of the coal and emits $40 \%$ of the $\mathrm{CO} 2$ from fossil fuel combustion [5]. Controlling the carbon emissions in the power sector plays a key role in curbing China's carbon emissions, considering that by 2020 China's carbon emissions will be still mainly affected by the power industry [6]. Power plants in China are mainly thermal, burning fossil fuels, which emit a great deal of pollutants and greenhouse gases. In fact, the annual power generation from coal accounts for more than $70 \%$ of the total generating capacity. Thus, in order to reduce carbon emissions from the power industry, the power generation from less coal and more clean energy is needed. Hydroelectric power, reducing environmental pollution, has played a prominent part in the electrification phase of the industrialization process [7]. In spite of rapid development in China, the further development of hydropower is still restricted due to unevenness of precipitation distribution [8] and increased methane and $\mathrm{CO} 2$ emissions from the lake because of deeper water and slower flowing speed after the emptying of reservoirs [9]. Many issues also exist in popularization of large-scale wind energy and solar energy. For example, wind power grid-connected of wind power turbine [10]. Moreover, wind power plants are located in the places where grid investments are insufficient, electric power construction is lag, the electric energy transmission is difficult. So, as a result, the local consumption demand is satisfied and electric energy is no longer needed. The solar photovoltaic industry faces many problems, such as severe overcapacity of PV, market immaturity, lack of matching network planning and financing difficulties [11]. Worse still, wind power and solar energy quality, including wind speed, blowing rate, the amount of light and radiation intensity, all change with climate variation, which can't ensure grid stability. Other new energy sources, such as geothermal energy [12], biomass energy [13], tidal energy [14], due to restrictions or imperfections from capital, technology, policy, and other factors, are still in start-up and immature phase, which can't be scaled up to wide use currently.

Based on the above analysis, hydropower, wind power and solar power fail to be used to curb the haze and carbon emissions. So nuclear is by far the best option for energy structure adjustment and haze governance. Meanwhile, for improving the environment, reducing carbon emissions, energy security and structural adjustment, nuclear has been expected to contribute to that in the worldwide. Many developing countries [15] have begun to focus on expanding nuclear power, such as Thailand will build nuclear power plants with electrical productivity of about $4000 \mathrm{MW}$ from 2010 to 2030 [16], Vietnam decides to build 14 nuclear power plants by 2030 , and realizes $10 \%$ of the total electric power provided by nuclear power in 20 years [17]. After the Fukushima accident, the nuclear power industry has been remaining depressed. However, the Chinese government plans to revive nuclear energy. The "long-term nuclear power development plan (2011-2020)" and "nuclear safety planning (2011-2020)" have been approved by the State Council of China on October 24, 2012, which shows clearly 40 million kilowatts of installed capacity and 20 million kilowatts of installed capacity under construction by 2015 , and 58 million kilowatts of installed capacity and 30 million kilowatts of installed capacity under construction by 2020. In short, expansion of nuclear power is important either for environmental protection and economy benefit or energy structure and safety [18].

\section{The Development of China's Nuclear Power}

\subsection{Development History of China's Nuclear Power}

Nuclear power industry originated in nuclear energy for military application [19], which is a great epoch-making event in the history of the world's energy. China has an approximately 70-year-old history of nuclear development. In 1956 the State Council of China began to focus on the peaceful use of atomic energy. The preparation of graphite cooling heap and relative research on nuclear power were implemented in 1958 [20]. Specific and further research on nuclear power, including reactor type, security, operation and location, were carried out during 1977 to 1984. And National Nuclear Security Administration (NNSA) and Ministry of Nuclear Industry were also established during that period [21]. Then China's nuclear power industry got initial development. Qinshan Nuclear Power Plant started construction in 1985, which closed the non-nuclear chapter in mainland China. Advanced international technologies were introduced to build nuclear plants from 1987 to 2003, such as Daya Bay plant (French technology), Qinshan Phase III (Canadian technology) and Tianwan Phase I (Russian technology). However, due to the Chernobyl disaster and poor domestic technology, massive growth of nuclear power in China failed to appear with merely six nuclear power 
stations constructed. Fortunately, China's nuclear power industry had a good developing time during 2004 to 2011, with fourteen nuclear-power plants built. Nuclear power in China, by the end of 2011, reached the total installed capacity of 12.55 million $\mathrm{KW}$, with twenty nuclear reactors and fourteen commercial operation units [22]. Given public concerns about safety caused by the Fukushima nuclear disaster, environmental protection and safety performance in
China's nuclear power industry were re-evaluated. And the proposed projects have been languishing, without restart so far.

Despite of late start and slow development, China's nuclear power industry still acquires some achievements during 1985 to 2014. And the corresponding development process has been shown in Figure 2 and Figure 3.

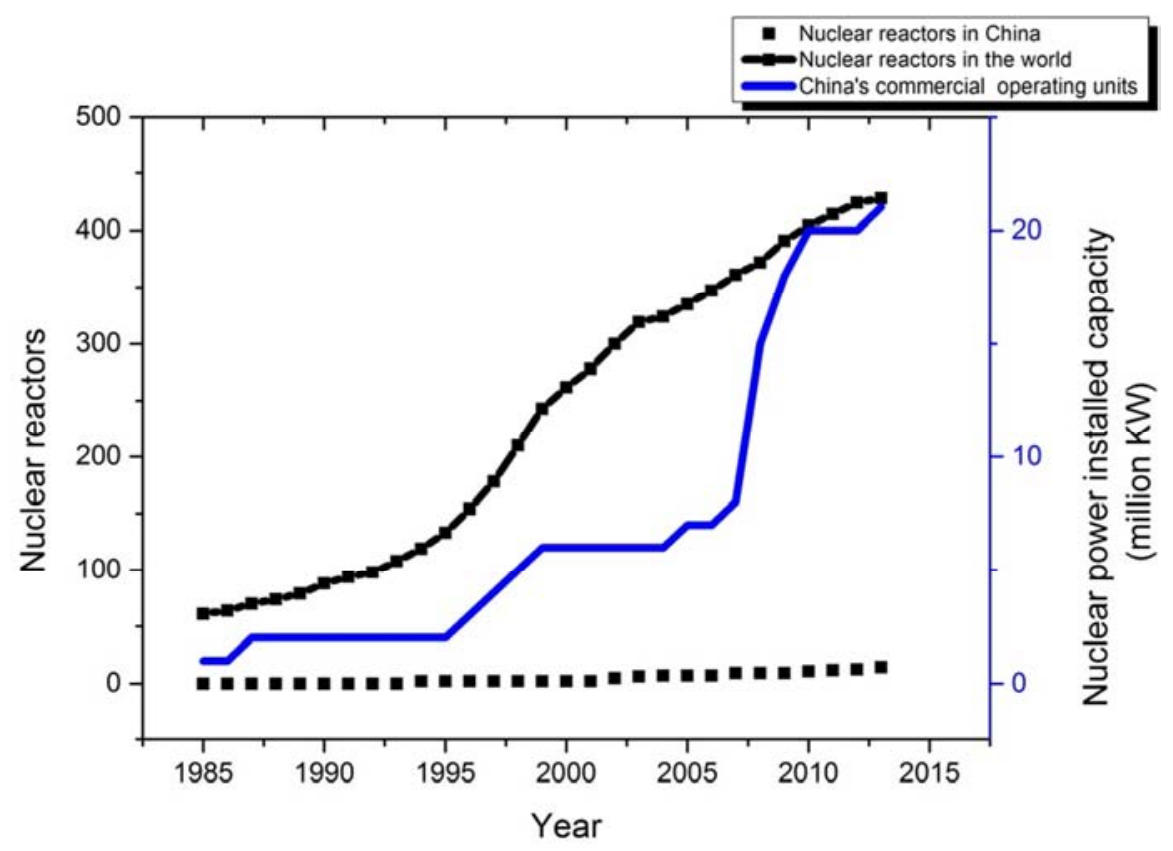

Figure 2. The number of nuclear reactor and commercial operating units in China from1985 to 2013.

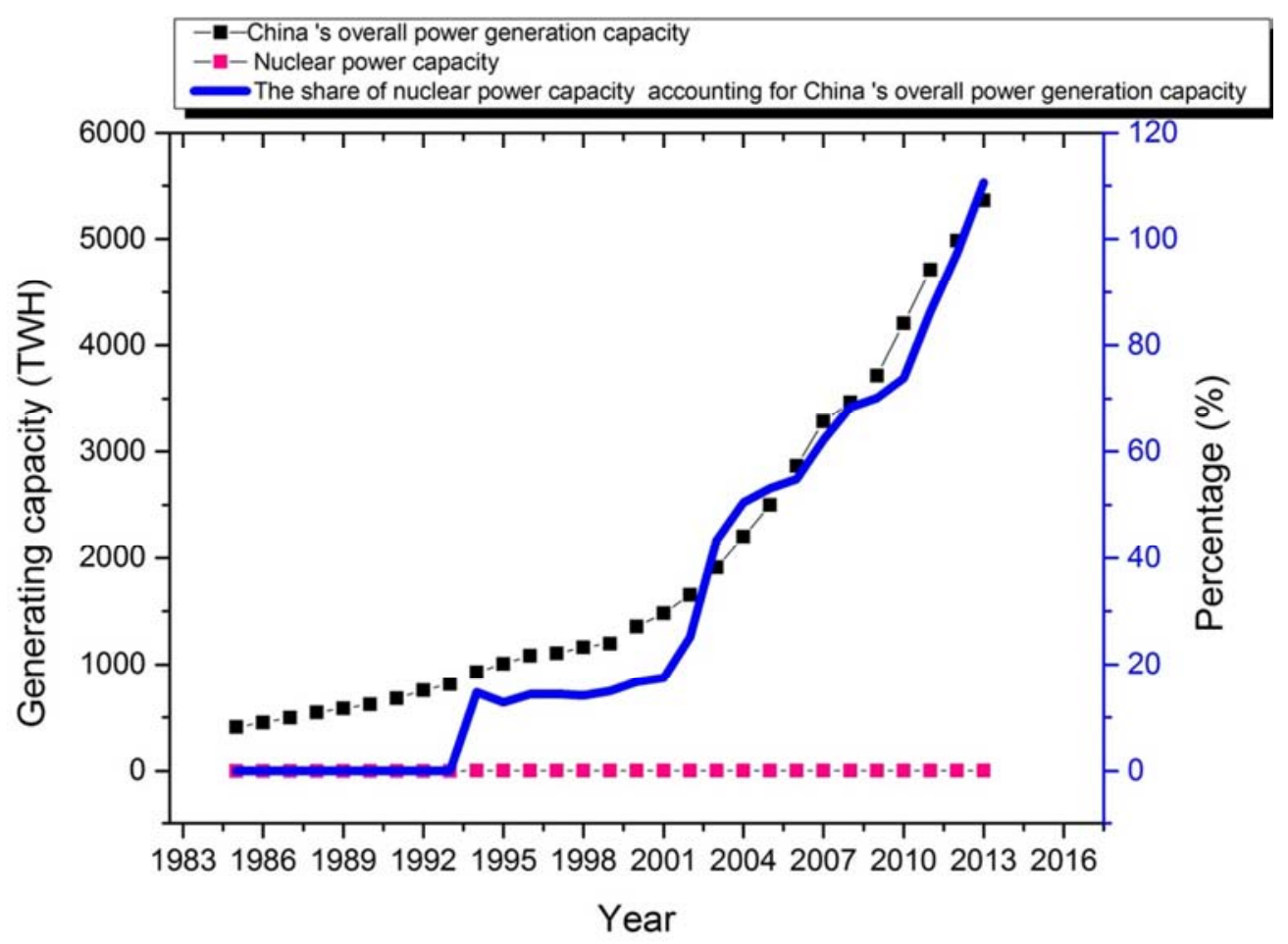

Figure 3. China's nuclear power capacity and the corresponding percentage of the total capacity from 1985 to 2013.

As can be shown in Figure 2, the number of nuclear reactors in China was trending ever-upward. Compared with the number of nuclear reactors in the world, China's nuclear reactor failed to grow in a sustained way. Some events may 
account for that, including the Chernobyl nuclear power plant accident in 1986, the restriction to electric power development by the Chinese government in 1998 and the Fukushima nuclear disaster in 2011.

As can be shown in Figure 3, nuclear generating capacity remained increasing. However, the share of nuclear power generation accounting for China's total generating capacity was in fluctuations, with two peaks appearing in 1994 and 2004 respectively, one doldrums in 2010. After 2010, nuclear generating capacity began to rise again without a huge rally.

\subsection{The Status Quo of Nuclear Power in China}

Eleven nuclear power plants, by August 2014, have been built in mainland China, and the number of commercial operation unit is nineteen sets. Ten nuclear power plants, with a total installed capacity of at least 19.6 million kilowatts, are currently under construction in mainland China, which is shown in Table 1. Nuclear power plants built or under construction are all coastal nuclear power plants. The proposed twenty-seven nuclear power plants in China, inland nuclear power plants accounting for approximately $74.1 \%$, show that great attention has been put on the inland nuclear power plants by the Chinese government. More thermal power in inland and power demand may explain that. At present, nuclear power installed capacity in mainland China has reached 16.42 million kilowatts, the annual generating capacity reaching $110.6 \mathrm{TWH}$ in 2013.

Table 1. Nuclear power plants under construction in mainland China.

\begin{tabular}{|c|c|c|c|c|c|c|}
\hline Serial number & Nuclear power plant & The number of units & Rated power (MW) & Start date & Technology source & The type of reactor \\
\hline 1 & Fuqing phase 1 & 2 & 1000 & Nov.21.2008 & France & PWR \\
\hline 2 & Qinshan Extension & 2 & 1100 & Dec.26.2008- & China & PWR \\
\hline 3 & Sanmen phase 1 & 2 & 1250 & Feb.26.2008 & America & PWR \\
\hline 4 & Taishan phase 1 & 2 & 1750 & Dec.21.2009- & France & PWR \\
\hline 5 & Haiyang phase 1 & 2 & 1250 & Dec.28.2009- & America & PWR \\
\hline 6 & Shidao bay phase 1 & 1 & 200 & Apr.01.2008 & China & HTR \\
\hline 7 & Changjiang phase 1 & 2 & 650 & Apr.25.2010 & China & PWR \\
\hline 9 & Xudabu phase 1 & 2 & 1000 & Mar.01.2010 & Unknown & PWR \\
\hline 10 & National demonstration & Unknown & 1400 & Jan.01.2010 & China & PWR \\
\hline
\end{tabular}

Its share of the total generating capacity is very small, despite of the increasing installed capacity and annual energy production of nuclear power in China, with the maximum only $2.29 \%$ in 2003 and only $2.06 \%$ in 2013 . The proportion of all kinds of energy and corresponding generating capacity in mainland China in 2013 has been shown in Figure 4.

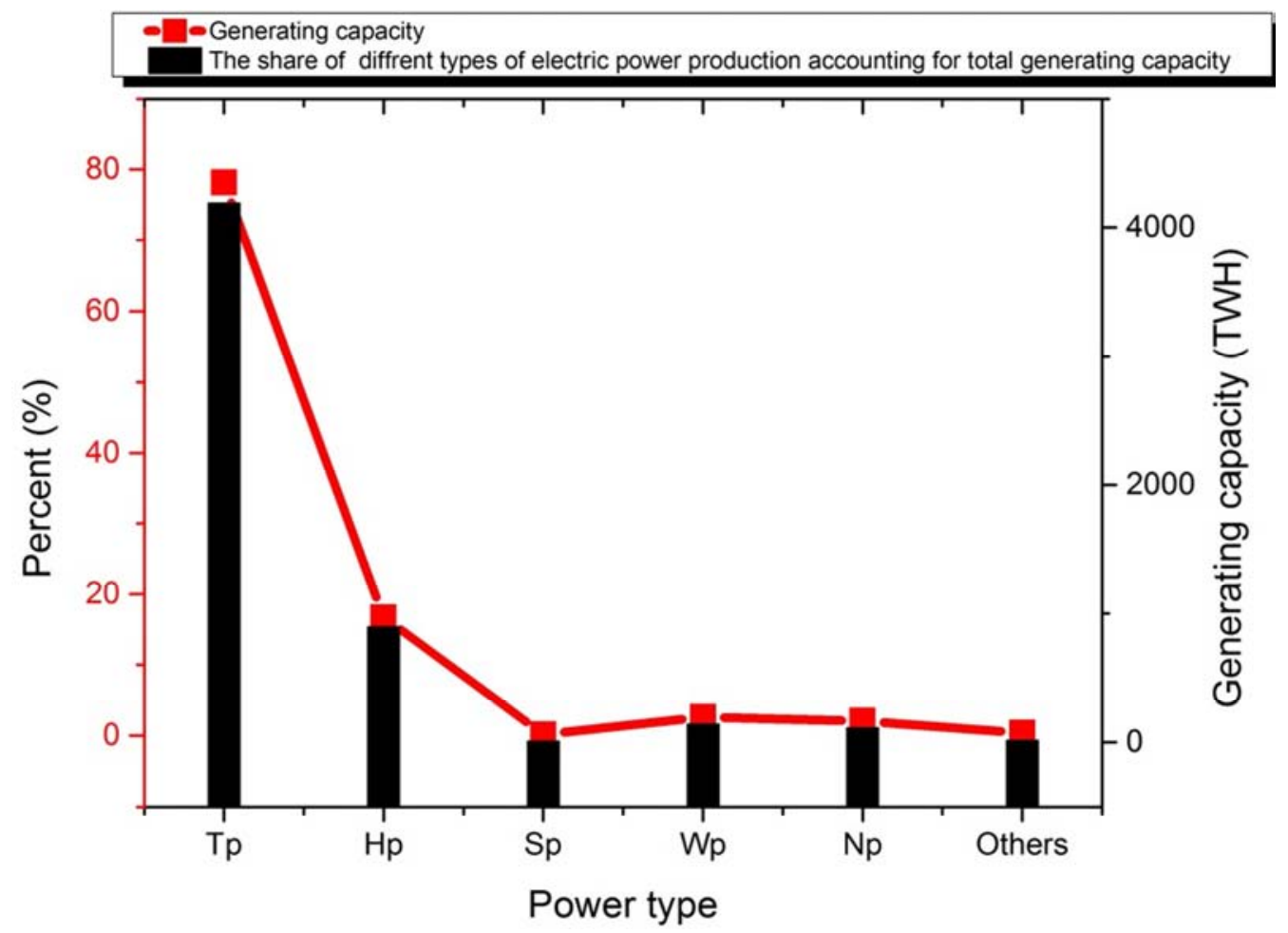

Figure 4. The proportion of all kinds of energy and corresponding generating capacity in mainland China in 2013.

As can be shown in Figure 4 (note: Tp refers to Thermal power, Hp refers to Hydroelectric power, Sp refers to Solar power, $\mathrm{Wp}$ refers to Wind power, $\mathrm{Np}$ refers to Nuclear power), nuclear power's share is weaker than wind power's, 
with the thermal power topping the list, followed by the hydropower. Some factors listed as follows may explain that. (1) Rich coal resources, mature construction and transform technology can reduce the generation cost in a thermal power station; (2) With abundance of water resources and lower technology barrier compared with nuclear power's, the Chinese government put more money and energy into the hydropower stations which also can prevent drought and flood; (3) Wind power grew at 8 percent a year during 2006 to 2011, thanks to the promulgation of the "Renewable Energy law" which present the cost compensation for renewable energy sources.

In spite of a huge gap in generating capacity, nuclear power in mainland China has a great potentiality and good perspective. The reasons for that are listed as follows. (1) According to Wei [23], vice president of the China electricity council, coal-fired power plants will not add by the 2030, which means added new electricity demands has to be met by other energies; (2) The thermal power in China is facing dual challenges to reduce carbon emissions and to lower the cost having climbed to $1.0302 \mathrm{CNY} / \mathrm{kwh}$ [24]; (3) The broad development of hydropower in China left less available water resources. And the ecological damage during hydropower construction and the rising cost hinder jointly sustainable development of the hydropower [25]; (4) Given core technologies relying on imports, development program not matching with power system planning, the solar and wind power fail to supply stable and sufficient electric power; (5) Due to the lack of reasonable industry planning and policies support, and lag of technologies, China's geothermal resources [12] and bioenergy [13] won't achieve massive growth. Consequently, it's urgent and necessary to develop nuclear power.

\subsection{China's Development Policies of Nuclear Power}

The Chinese government attaches great importance to the development of nuclear power, guiding and adjusting the policies according to the practical situations. In order to regulate and promote the development of the nuclear power industry, the government introduced many policies and regulations since 2003, which is shown in Table 2.

Table 2. Industry policies for China's nuclear energy.

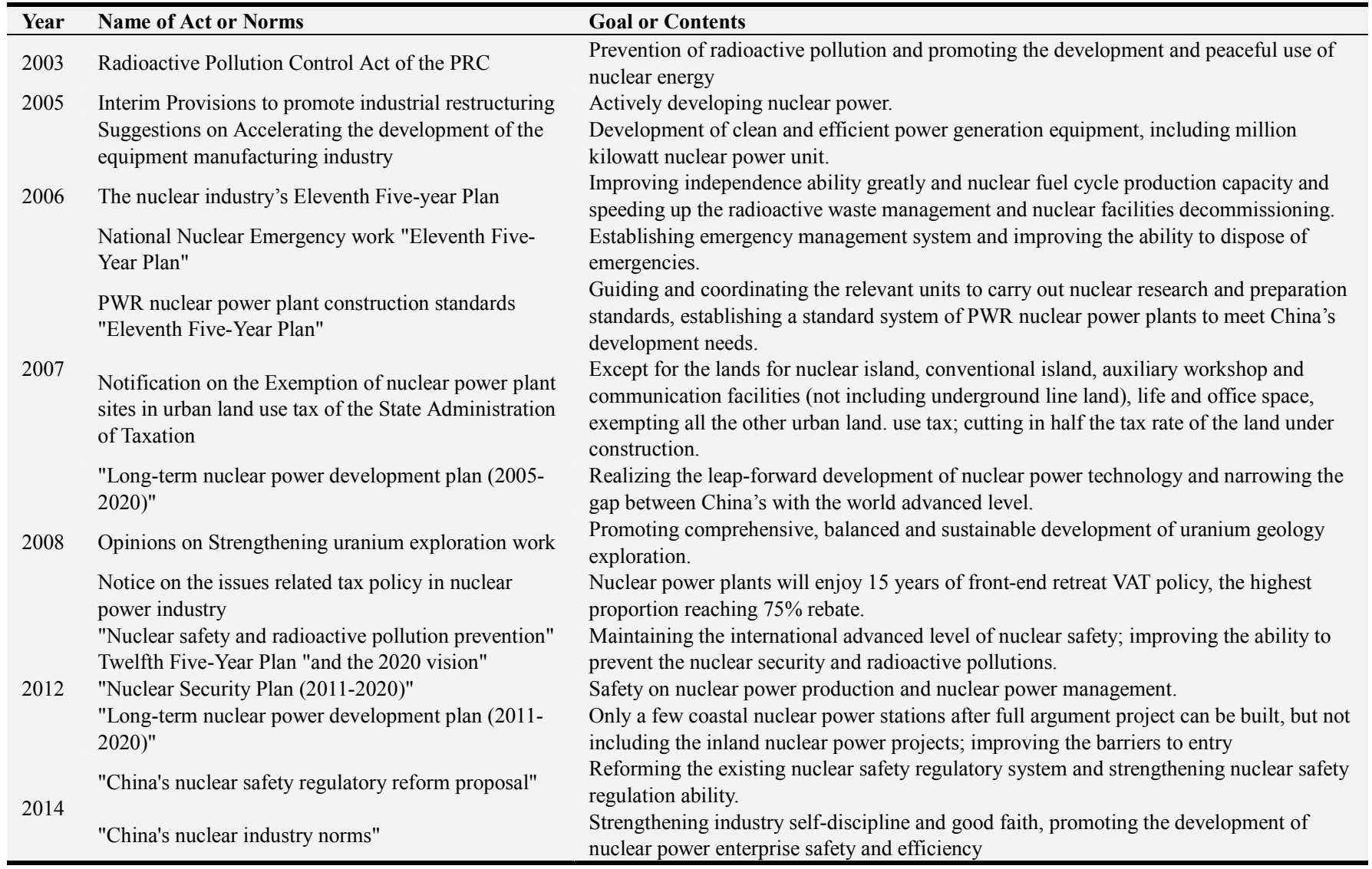

"Radioactive Pollution Control Act of the PRC", National Nuclear Emergency work "Eleventh Five-Year Plan" and "China's nuclear safety regulatory reform proposal" focus on safety regulations and specifications, which shows the Chinese government's emphasis on plant security. "Interim Provisions to promote industrial restructuring" points out it's necessary to develop actively nuclear power. "Suggestions on accelerating the development of the equipment manufacturing industry", PWR nuclear power plant construction standards "Eleventh Five-Year Plan" and "Opinions on strengthening uranium exploration work" regulate the standard system of the equipment, raw materials 
and construction process in nuclear power industry respectively. However, detailed orders are lacking. "Notification on the Exemption of nuclear power plant sites in urban land use tax of the State Administration of Taxation" and "Notice on the issues related tax policy in nuclear power industry" regulate tax breaks and subsidies, which is substantial support for the nuclear power industry.

For the development goals of China's nuclear power, the corresponding outlook has been presented in different stages of planning. The goal in the "nuclear industry's Eleventh Five-year Plan" is to improve significantly the scientific research level to meet the economic construction and national security. The goal in the "Long-term nuclear power development plan (2005-2020)" is to ensure installed capacity of 40 million KW, annual power generation of 260$280 \mathrm{TWH}$, added installed capacity of 23 million KW and installed capacity of 18 million KW under construction by the end of 2020. The goal in the "Long-term nuclear power development plan (2011-2020)" is to ensure installed capacity of 40 million $\mathrm{KW}$ and installed capacity of 20 million KW under construction by 2015 , installed capacity of 58 million $\mathrm{KW}$ and installed capacity of 30 million $\mathrm{KW}$ under construction by 2020 .

\section{Status Quo and Contribution of China's Nuclear Carbon Emissions}

\subsection{Status Quo of China's Carbon Emissions}

China's rapid economic growth consumed a huge number of energy fuel and further brought soaring carbon emissions. Carbon emissions in china from 2000 to 2013 are shown in Figure 5.

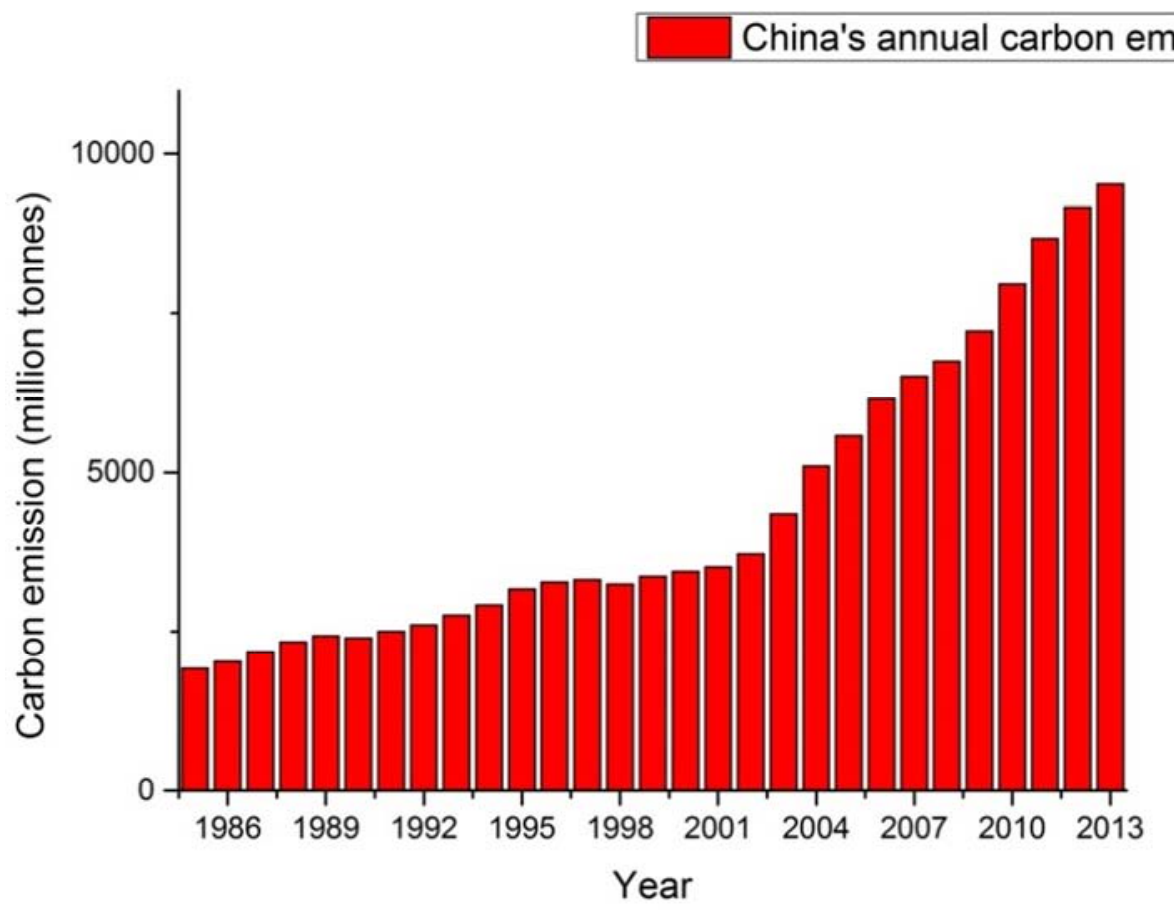

Figure 5. Carbon emissions in china from 2000 to 2013.

As can be shown in Figure 5, carbon emissions in china have risen from 3429.9 million tons in 2000 to 9524.3 million tons in 2013, with continuous rising and an average carbon emissions growth of 7.84 percent a year. From the perspective of the growth rate, it sustained the growth during 2000 to 2004, with the peak appearing in 2004 when it reached $17.44 \%$. The reasons for that are listed as follows. Firstly, since 1998, in response to the Asian economic crisis, the Chinese government implemented a proactive fiscal policy to expand domestic demand, which brought economic recovery in 2000 and 2001. Then, the Chinese government established the long-term policy of stimulating domestic demand and Implemented expansionary fiscal policies, which contributed to fully stimulating economic growth and to increasing further carbon emissions [26]. However, the decoupling between GDP and carbon emissions happened during 2005 to 2008 [27], which showed GDP growth was rising with the decreasing rate of carbon emissions at the same time. Some key factors, including energy consumption structure adjustment and rising energy efficiency brought by improving energy saving technology and the upgrading industrial structure, can explain that. And since 2008, the decoupling disappeared. Moreover, China's carbon emissions growth rate declined rapidly from $10.25 \%$ in 2010 to $3.91 \%$ in 2013, which benefited from the Eleventh Five-year Plan [28] and the "twelfth five-year" plan for energy efficiency and emission reduction [29]. Given the rapid declines of carbon emissions growth rate and in-depth and detailed emissions reduction measures, it's the best time to further reduce the carbon emissions by building more nuclear plants, which will eventually realize the carbon reduction target put forward at Copenhagen. 


\subsection{The Contribution of China's Nuclear Power Carbon Reduction}

A large share of China's carbon emissions is produced by the electricity sector. The proportion of carbon emissions produced by the power sector was $48.3 \%$, with the manufacturing sector accounting for $33.2 \%$, the transportation $6.9 \%$ and others $11.5 \%$ in 2009 [30]. Due to the most carbon emissions from the electric power, it is the critical point of reducing carbon emissions. Typically, nuclear power is considered to be zero emissions from nuclear power, but carbon emissions still exist in the whole life cycle, such as the production and transportation of nuclear fuel and the construction of nuclear chain. Nevertheless, the Greenhouse Gases Emission Factor (GGEF) for nuclear power chain of China is $13.7 \mathrm{~g}$ equivalent $\mathrm{CO} 2(\mathrm{kWeh})-1$, with GGEF for hydropower $107.6 \mathrm{~g}$ equivalent $\mathrm{CO} 2$ (kWeh)-1, GGEF for thermal power about $1300 \mathrm{~g}$ equivalent $\mathrm{CO} 2(\mathrm{kWeh})-1$ [31]. We can draw a conclusion that the potential for carbon reduction of nuclear power is still great.

In order to calculate the carbon reductions from China's nuclear power, ACM0002 algorithm in literature [32] is adopted in this paper. ACM0002 can be described as formula (1).

$$
\left\{\begin{array}{l}
N E R_{i}=N E G_{i} * E F_{i} \\
E F_{i}=\omega_{O M} * E F_{O M_{, i}}+\omega_{B M} * E F_{B M,_{i}} \\
\omega_{O M}+\omega_{B M}=1
\end{array}\right.
$$

Where $N E R_{i}$ is the $\mathrm{CO} 2$ emission reduction of nuclear power generating units in the ith year, $N E G_{i}$ is the generated electrical energy of nuclear power generating units in the ith year, $E F_{\mathrm{i}}$ is the nuclear power generating units instead of grid electricity baseline emission factor, $E F_{O M, \mathrm{i}}$ is the $\mathrm{OM}$ emission factor, $E F_{B M, \mathrm{i}}$ is the $\mathrm{BM}$ emission factor. $\omega_{O M}$ and
$\omega_{B M}$ are weights, and the default is 0.5 .

$$
\left\{\begin{array}{l}
E F_{\text {grid }, O M, s i m p l y, i}=\frac{\sum_{m} F C_{m, i} \bullet N C V_{m, i} \bullet E F_{C O 2, m, i}}{E G_{i}} \\
E F_{\text {grid }, B M, i}=\frac{\sum_{n} E G_{n, i} \bullet E F_{E L, n, i}}{\sum_{n} E G_{n, i}}
\end{array}\right.
$$

Where $E F_{\text {grid, } O M, \text { simply,i }}$ is the simple operating margin $\mathrm{CO} 2$ emission factor in the ith year, $F C_{\mathrm{m}, i}$ is the consumption of $\mathrm{m}$ which is the fuel in power system in the ith year, $N C V_{\mathrm{m}, i}$ is the net heating value of $\mathrm{m}$ which is the fuel in power system in the ith year, $E F_{C_{2}, m, i}$ is the $\mathrm{CO} 2$ emission factor of $\mathrm{m}$ which is the fuel in power system in the ith year, $E G_{\mathrm{i}}$ is the electric quantity that power systems provide to the grid in the ith year, $m$ is the whole fossil fuel consumed in the grid, I is the last three years of data, $E F_{\text {grid }, B M, i}$ is the BM emission factor in the i year, $E F_{E L, n, i}$ is the emission factor of the $\mathrm{n}$ sample unit in the ith year, is the electric quantity that the $n$ sample unit provides to the grid in the ith year.

According to NDRC (National Development and Reform Commission), Chinese regional grid baseline emission factor (2009-2013) can be available. Related data are listed in table 3. North China power grid includes Beijing, Tianjin, Hebei, Shanxi, Shandong and Inner Mongolia; Northeast China power grid includes Liaoning, Jilin and Heilongjiang; East China power grid includes Shanghai, Jiangsu, Zhejiang, Anhui and Fujian; Central China power grid includes Henan, Hubei, Hunan, Jiangxi, Sichuan and Chongqing; Northwest China power grid includes Shanxi, Gansu, Qinghai, Ningxia and Xinjiang; Before 2009, China Southern Power Grid includes Guangdong, Guangxi, Yunnan and Guizhou, then Hanna power grid are added to China Southern Power Grid. The Tibet Autonomous Region, Hong Kong SAR, Macao SAR and Taiwan Province are excluded.

\begin{tabular}{|c|c|c|c|c|c|}
\hline \multicolumn{6}{|c|}{ Chinese OM emission factor $\left(E F_{g r i d, o M, \text { simply,i }}\right)$ and BM emission factor $\left(E F_{g r i d, B M, i}\right)(\mathrm{tCO2} / \mathrm{MWh})$} \\
\hline Region & 2009 & 2010 & 2011 & 2012 & 2013 \\
\hline North China Power grid & $(1.0069,0.7802)$ & $(0.9914,0.7495)$ & $(0.9803,0.6426)$ & $(1.0021,0.5940)$ & $(1.0302,0.5777)$ \\
\hline Northeast China Power grid & $(1.1293,0.7242)$ & $(1.1109,0.7086)$ & $(1.0852,0.5978)$ & $(1.0935,0.6104)$ & $(1.1120,0.6117)$ \\
\hline East China power grid & $(0.8825,0.6826)$ & $(0.8592,0.6789)$ & $(0.8367,0.6622)$ & $(0.8244,0.6889)$ & $(0.8100,0.7125)$ \\
\hline Central China Power grid & $(1.1255,0.5802)$ & $(1.0871,0.4543)$ & $(1.0297,0.4191)$ & $(0.9944,0.4733)$ & $(0.9779,0.4990)$ \\
\hline Northwest China Power grid & $(1.0246,0.6433)$ & $(0.9947,0.6878)$ & $(1.0001,0.5851)$ & $(0.9913,0.5398)$ & $(0.9720,0.5115)$ \\
\hline China Southern Power Grid & $(0.9987,0.5772)$ & $(0.9762,0.4506)$ & $(0.9489,0.3157)$ & $(0.9344,0.3791)$ & $(0.9223,0.3769)$ \\
\hline Hainan power grid & $(0.8154,0.7297)$ & $(0.7972,0.7328)$ & -- & -- & -- \\
\hline
\end{tabular}

Table 3. Chinese OM emission factor (2009-2013).

Thus, we can obtain the EF (the nuclear power generating units instead of grid electricity baseline emission factor). In order to calculate the electricity generated by nuclear plants in regional power grid, appropriate method is applied in this paper.

$$
E_{i}=I C_{i} * H_{i}
$$

Where $E_{i}$ is the electricity generated by nuclear plants in regional power grid in the ith year, $I C_{i}$ is the installed capacity in regional power grid in the ith year, $H_{i}$ is the available hours in the ith year.

According to literature [33], this paper assumes $H_{i}=0.5 *(7772+7841)$. Then the electricity generated by nuclear plants and $\mathrm{CO} 2$ emission reduction in corresponding regional power grid can be calculated which are shown in table 4. 
Table 4. The electricity generated by nuclear plants and CO2 emission reduction in corresponding regional power grid (2009-2013).

\begin{tabular}{llllll}
\hline \multicolumn{2}{l}{ The electricity generated by nuclear plants $\left(\boldsymbol{E}_{\boldsymbol{i}}\right) \mathbf{( T W h )}$ and CO2 emission reductions $\left(\mathbf{N E R}_{\boldsymbol{i}}\right)($ Million tons) in corresponding regional power grid } \\
\hline Region & $\mathbf{2 0 0 9}$ & $\mathbf{2 0 1 0}$ & $\mathbf{2 0 1 1}$ & $\mathbf{2 0 1 2}$ & $\mathbf{2 0 1 3}$ \\
\hline North China Power grid & $(0,0)$ & $(0,0)$ & $(0.81318,0.65985)$ & $(1.95163,1.55749)$ & $(1.95163,1.56901)$ \\
Northeast China Power grid & $(0,0)$ & $(0,0)$ & $(0,0)$ & $(0,0)$ & $(4.55379,3.92469)$ \\
East China power grid & $(40.40644,31.62006)$ & $(41.25215,31.72496)$ & $(45.48067,34.08549)$ & $(49.28634,37.29251)$ & $(55.10869,41.95149)$ \\
Central China Power grid & $(0,0)$ & $(0,0)$ & $(0,0)$ & $(0,0)$ & $(0,0)$ \\
Northwest China Power grid & $(0,0)$ & $(0,0)$ & $(0,0)$ & $(0,0)$ & $(0,0)$ \\
China Southern Power Grid & $(30.82006,24.28467)$ & $(32.77169,23.37932)$ & $(43.83090,27.71428)$ & $(46.43306,30.49491)$ & $(46.43306,30.16292)$ \\
Hainan Power grid & $(0,0)$ & $(0,0)$ & - & - & \\
Sum (TWH, million tons) & $(71.22651,55.90473)$ & $(74.02384,55.10429)$ & $(90.12474,62.45962)$ & $(97.67102,69.34492)$ & $(108.04716,77.6081)$ \\
\hline
\end{tabular}

According to table 4, carbon emission reductions (20092013) from nuclear power plants account for $0.77 \%, 0.69 \%$, $0.72 \%, 0.76 \%$ and $0.81 \%$ of total carbon emissions respectively. According to the data from Carbon Dioxide Information Analysis Center (CDIAC) and Ministry of Environmental Protection of People's Republic of China (MEPPRC), carbon emissions from fossil fuels in China from 2009 to 2013 are 2097.685 million tons, 2259.856 million tons, 2522.260 million tons, 2749.794 million tons, 2952.528 million tons respectively. Thus, only from the perspective of fossil fuel, nuclear power contributed to $2.65 \%, 2.43 \%$, $2.48 \%, 2.53 \%, 2.61 \%$ of fossil fuel emissions reductions in China only with $1.89 \%, 1.76 \%, 1.83 \%, 1.95 \%, 2.06 \%$ of total electricity generation during 2009 to 2013 .

\section{Scenario Analysis of China's Nuclear Potential to Reduce Emissions}

In this paper, the baseline scenario of China's power generation capacity in "Energy Strategy Report (2009)" by the National Energy Board [34] is set for standards-based, which avoids the predicted risk brought by low solution and high one. About China's nuclear power development scenario analysis, this paper set the American scenario, planning scenario and low scenario. The American scenario is in accordance with nuclear power development speed and planning in US. In this scenario, the nuclear power generating capacity will realize $2 \%$ in 2015 and $12 \%$ in 2020 respectively of China's total power generation in the corresponding year, and $18 \%$ in 2025 . The planning scenario is in accordance with "long-term nuclear power development plan (2011-2020)". In this scenario, China's nuclear power will reach the total installed capacity of $58 \mathrm{GW}$ and the total installed capacity of $30 \mathrm{GW}$ under construction in 2020 , and the total installed capacity of $90 \mathrm{GW}$ in 2020. The low scenario refers to nuclear power developing with the current proportion $(2.06 \%$ in 2013$)$ of China's total electricity generation. Consequently, China's nuclear power generating capacity in the future under the three scenarios can be obtained, which is shown in Figure 6.

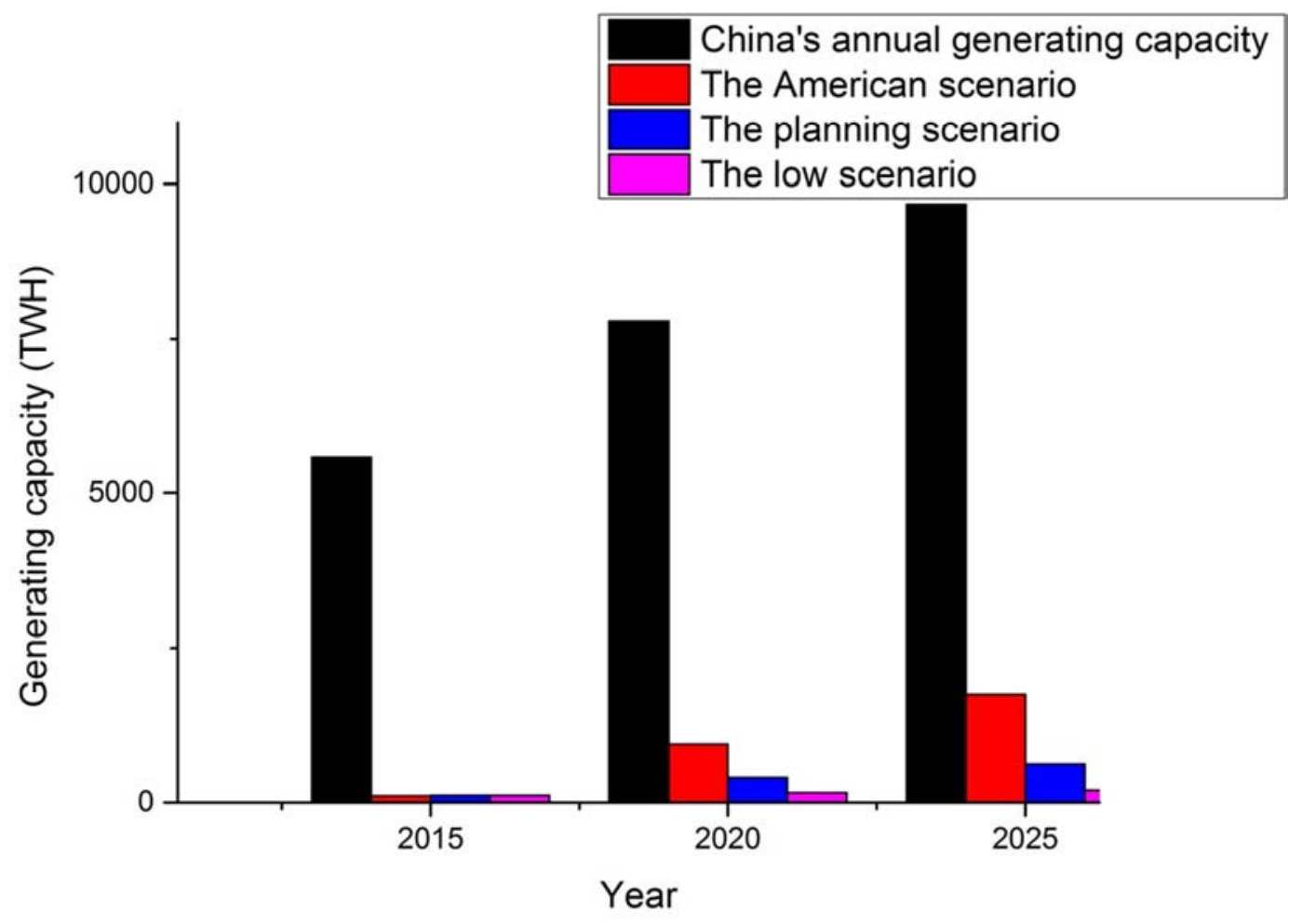

Figure 6. China's nuclear power generating capacity in the future under the three scenarios. 
Thus, China's nuclear power reduction potential under the three different scenarios from 2015 to 2025 can be obtained based on the average OM and the EM during 2009 to 2013, which is shown in table 5.

Table 5. China's nuclear power reduction potential under the three different scenarios.

\begin{tabular}{llll}
\hline Time (Year) & Scenario & Nuclear power generation (TWh) & The CO2 emission reductions (Million tons) \\
\hline \multirow{2}{*}{2013} & Status quo & 108.05 & 77.61 \\
& American scenario & 111.8 & 87.65 \\
& Planning scenario & 115.2 & 90.32 \\
& Low scenario & 115.15 & 90.28 \\
& American scenario & 934.8 & 732.87 \\
2020 & Planning scenario & 403.96 & 316.70 \\
& Low scenario & 160.47 & 125.81 \\
& American scenario & 1740.6 & 1364.61 \\
& Planning scenario & 626.83 & 491.43 \\
\end{tabular}

By the analysis of China's nuclear power reduction potential under three scenarios, the American scenario gives a huge amount of carbon dioxide reduction. The $\mathrm{CO} 2$ reduction in American scenario estimated to be approximately 2.78 times and 8.74 times respectively as compared to the Planning scenario and Low Speed scenario by 2025 .

\section{Suggestions}

Attention should be paid to that the development of nuclear power can reduce the $\mathrm{CO} 2$ emissions in China greatly. It's the best time for China to promote nuclear power, given that the growth rate of carbon emissions in China remains decreasing from 2010. Undoubtedly, the Chinese Government plays a decisive role in promoting nuclear power. However, the Chinese government is deterred by the accident at the Fukushima nuclear facility in Japan to push along to the new stage of nuclear power development. In short, the suggestions for nuclear power should be made positively listed as follows:(1) Currently the Chinese Government should restart nuclear energy explicitly and confidently; (2) The Chinese Government should make a bold and adequate development plan for nuclear power, including more planning for inland nuclear power stations and greater Installed capacity; (3) The Chinese Government should provide direct substantive support for nuclear power development, including improving the ability of public perception for nuclear power and acceptability, accommodating relocated households better, providing higher fund subsidy, and so on.

\section{Conclusion}

The development of nuclear power and the corresponding potential for reducing $\mathrm{CO} 2$ emissions in China have been discussed in this paper. Based on the above analysis, the conclusions could be summarized as follows: (1) the carbon reduction potential of China's nuclear power is great, reaching 1364.61 million tons carbon reduction in 2025 under the American scenario. However, the development of China's nuclear power is very slow, and is in a sign of hesitation; (2) hydroelectric power, wind power and solar power generation fail to reduce the carbon substantially and remarkably, due to limited potential and their peculiarity; (3) inadequate plan and support for the development of China's nuclear power are rather obvious. The latest "Long-term nuclear power development plan (2011-2020)" shows that China's nuclear power will reach installed capacity of 58 million KW and installed capacity of 30 million KW under construction by 2020 , which is so few compared with China's total power generation in 2020 .

\section{Acknowledgements}

Project supported by the Fundamental Research Funds for the Central Universities (No.2015XS27), the National Nature Science Foundation of China (No.71271085).

\section{References}

[1] International Energy Agency. 2014. BP Statistical Review of World Energy.

[2] Zhang, Zhongxiang. 2011. In what format and under what timeframe would China take on climate commitments: A roadmap to 2050. International Environmental Agreements: Politics, Law and Economics 3: 245-259.

[3] The 12th five-year development plan for carbon emission 2012. [EB/OL].

http://www.gov.cn/gongbao/content/2012/content_2217291.ht $\mathrm{ml}$.

[4] U. S. EPA. 2014. Overview of Greenhouse Gases. $<\mathrm{http} / / / w w w . e p a . g o v /$ climatechange/ghgemissions/gases/CO2. html>.

[5] Qixin Chena, Chongqing Kanga, Hao Minga, Zeyu Wanga, Qing Xiaa, Guoxin Xub, c. 2014. Assessing the low-carbon effects of inter-regional energy delivery in China's electricity sector. Renewable and Sustainable Energy Reviews 32: 671-683.

[6] Liwei Liua, Haijing Zonga, Erdong Zhaoa, Chuxiang Chena, Jianzhou Wangb. 2014. Can China realize its carbon emission reduction goal in 2020: From the perspective of thermal power development. Applied Energy 124: 199-212.

[7] R. Sternberg. 2010. Hydropower's future, the environment, and global electricity systems. Renewable and Sustainable Energy Reviews 14: 713-723. 
[8] Hailun Huang, Zheng Yan. 2009. Present situation and future prospect of hydropower in China. Renewable and Sustainable Energy Reviews 13: 1652-1656.

[9] XiaoLin Changa, Xinghong Liub, Wei Zhoua. 2010. Hydropower in China at present and its further development. Energy 4400-4406.

[10] Chen Xiao-lei; Yang Yue-long; Shi Xiao-ron. 2014. Summary of wind power grid-connected problems in China. Telecom Power Technology 2: 8-11.

[11] Honghang Suna, Qiang Zhib, Yibo Wangc, Qiang Yaoa, Jun Sud. 2014. China's solar photovoltaic industry development: The status quo, problems and approaches. Applied Energy 118: $221-230$

[12] Xin-gang Zhao, GuanWan. 2014. Current situation and prospect of China's geothermal resources. Renewable and Sustainable Energy Reviews 32: 651-661.

[13] Zhao Xingang, Liu Pingkuo. 2014. Focus on bioenergy industry development and energy security in China. Renewable and Sustainable Energy Reviews 32: 302-312.

[14] Hong-wei Liu, Shun Ma, Wei Li, Hai-gang Gu, Yong-gang Lin, Xiao-jing Sun. 2014. A review on the development of tidal current energy in China. Renewable and Sustainable Energy Reviews 15: 1141-1146.

[15] Alessandra Dalla Valle, Claudia Furlan. 2014. Diffusion of nuclear energy in some developing countries. Technological Forecasting \& Social Change 81: 143-153.

[16] Parinya Pongsoi, Somchai Wongwises. 2013. A review on nuclear power plant scenario in Thailand. Renewable and Sustainable Energy Reviews 24: 586-592.

[17] Bao Guangjiang. 2013. Vietnam's Nuclear Power Development Strategy and Its Impact on the International Relations. Southeast Asian Studies 2: 54-61.

[18] Ricardo Luis Pereira dos Santos, Luiz Pinguelli Rosa, Maurício Cardoso Arouca, Alan Emanuel Duailibe Ribeiro. 2013. The importance of nuclear energy for the expansion of Brazil's electricity grid. Energy Policy 60: 284-289.

[19] Ma Chi. 1991. History and Policies of China's nuclear power development. Management World 3: 212.

[20] Li Xiaoping. 2012. Policy analysis of China's nuclear power industry development. Enterprise Economy 5: 164-167.

[21] Feng Zhiqing. 2009. China Nuclear Events. China Investment 5: 63 .
[22] Xiao Xinjian. 2012. Development, future trends and policy recommendations of china's nuclear power in 2011. Energy of China 34:18-23. <http://www.china5e.com/news/news864557-1.html>

[23] Xu Weili, Li Yanan, Wang Huajun. 2014. Comparative analysis of the cost of coal-fired power and wind power entirely. Wind Energy 06: 50-55.

[24] Chen Yunhua, Wu Shiyong, Ma Guangwen. 2013. Trends and prospects of hydropower development in China. Journal of Hydroelectric Engineering 06: 1-4+10.

[25] Research Group of China Economics Development Report, Renmin University of China. 2004. Adjusting Chinese economic structures during the important strategic opportunity period. Economic Theory and Business Management 04: 5-14.

[26] PENG Jiawen, HUANG Xianjin, ZHONG Taiyang, ZHAO Yuntai. 2011. Decoupling Analysis of Economic Growth and Energy Carbon Emissions in China. Resources Science 04: 626-633.

[27] Zhao Jiarong. 2010. The effect of 11th five-year plan for energy conservation and emissions reduction and preliminary consideration of the 12 th five-year energy-saving ideas. China Economic \& Trade Herald 24: 24-25.

[28] Ze Hua. 2012. More detailed planning and more stringent indicator--energy conservation and emissions reduction the 12th five-year plan interpretation. Sinopec Monthly 10: 26-27.

[29] National Energy Board Development Planning Division, State Grid Corporation of Development Planning Department, State Grid Energy Research Institute. Energy Data Book 2012.

[30] Pan Ziqiang, Ma Zhonghai, Li Xutong, Wu Tao, Xiu Bbinlin. 2001. Comparative study of impacts of coal chain and nuclear power chain in china on health, environment and climate. Radialization Protection 03: 129-145.

[31] Huang Wenjie, Yang Guang, Liu Da. 2009. China nuclear power and its role in mitigating $\mathrm{CO} 2$ emission. East China Electric Power 04: 529-532.

[32] Chen Fangqiang, Wang Qingsong. 2012. China Needs to Continue to Develop Nuclear Energy in the New Period. Energy Technology and Economics 06: 1-6.

[33] Sui Xin, Liao Wengen. 2010. An intensifying method for extracting drainage networks in a plain with violent human activities. Journal of China Institute of Water Resources and Hydropower Research 02: 133-137. 